\title{
Protocol
}

\section{Desiccation of Hypsibius exemplaris}

Thomas C. Boothby ${ }^{1}$

Department of Chemistry, University of North Carolina at Chapel Hill, Chapel Hill, North Carolina 27599

Many species of tardigrades can survive severe water loss, but different species tolerate different desiccation conditions. Hypsibius exemplaris is able to survive desiccation after an initial period of slow drying, as described here. This protocol will likely work for other tardigrade species as well. Drying of tardigrades can be used for probing the mechanistic underpinnings of desiccation tolerance, as well as for practical purposes such as shipping and long-term storage of the animals.

\section{MATERIALS}

It is essential that you consult the appropriate Material Safety Data Sheets and your institution's Environmental Health and Safety Office for proper handling of equipment and hazardous materials used in this protocol.

Reagents

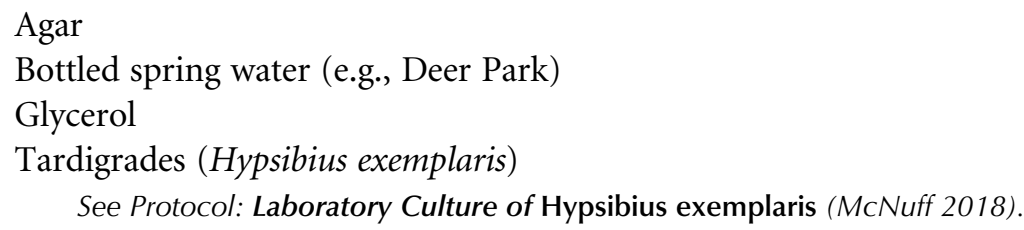

Equipment

Desiccator with Drierite or silica gel

Dissecting microscope

Glass watch dish

Hot plate at $100^{\circ} \mathrm{C}$

Hygrometer

Micropipette

Plastic Petri dishes $(35 \mathrm{~mm}$, with lids)

Small plastic box $(\sim 5$ inch $\times 5$ inch $\times 10$ inch, with lid $)$

\section{METHOD}

\section{Prepare Tardigrades}

Food should be absent from the guts of the tardigrades before desiccation. Perform these steps on the day before desiccation.

\footnotetext{
${ }^{1}$ Correspondence: tboothby@gmail.com From the Emerging Model Organisms collection.

(C) 2018 Cold Spring Harbor Laboratory Press

Cite this protocol as Cold Spring Harb Protoc; doi:10.1101/pdb.prot102327
} 
T.C. Boothby

1. Pour $\sim 2 \mathrm{~mL}$ of spring water into a new 35-mm plastic Petri dish.

2. Isolate tardigrades from food by transferring them to the new dish containing spring water. Starve the tardigrades by leaving them in the dish overnight at room temperature.

Prepare a Humidified Chamber

Perform these steps on the day before desiccation.

3. Place a glass watch dish containing $\sim 5 \mathrm{~mL}$ of a $10 \%$ glycerol solution (1 part glycerol, 9 parts spring water) in a small plastic box with a lid.

4. Leave the box overnight $(\sim 16 \mathrm{~h})$ at room temperature.

5. Use a hygrometer to check the humidity in the chamber.

The relative humidity should be $>90 \%$ after $\sim 16 \mathrm{~h}$. See Troubleshooting.

Prepare Agar-Coated Petri Dish Lids

Prepare agar-coated lids on the day of use. Do not store or reuse coated lids.

6. Prepare a stock of a $2 \%$ agar solution using bottled spring water, and boil it.

7. Pipette $300 \mu \mathrm{L}$ of the boiling agar solution into the lid of a $35-\mathrm{mm}$ Petri dish.

Discard the dish itself; only the lid will be used.

8. Working quickly, use the tip of the pipette to spread the agar solution evenly around the entire lid. Minimize excess agar and uneven distribution.

9. Tilt the lid on its side so that excess agar pools to one side. Remove and discard excess agar from the side of the lid with a pipette.

10. Allow the thin agar coating to solidify and dry for 5-10 min.

Use the coated lids immediately.

Desiccate Tardigrades

11. Transfer starved tardigrades from Step 2 to the agar-coated dish lid from Step 10 using a micropipette. Minimize the amount of water that is transferred with the tardigrades.

12. Remove excess water from the dish lid using a micropipette.

13. Place the agar-coated lid containing the tardigrades in the humidified chamber from Step 5 , and incubate overnight $(\sim 16 \mathrm{~h})$.

14. Remove the lid from the humidified chamber, and inspect the dried samples using a dissecting microscope.

Specimens should have adopted a rounded tun-like appearance. See Troubleshooting.

15. Keep tardigrades at ambient humidity ( $\sim 40 \%$ relative humidity) for $24 \mathrm{~h}$, and then store uncovered in a desiccator at room temperature.

Rehydrate Tardigrades

16. Pipette $2 \mathrm{~mL}$ of bottled spring water into dish lid.

When observed under a dissecting microscope, tardigrades that have been stored dry for $24 \mathrm{~h}$ begin to exit their tun state within $10 \mathrm{~min}$. Coordinated movement is typically observed within 30-60 min. Survival is typically $\sim 80 \%$ and is judged by scoring for coordinated movement and response to stimuli (touching with a micropipette tip). 
Problem (Step 5): The relative humidity is $<90 \%$.

Solution: Remake the $10 \%$ glycerol solution and repeat Steps 3-5.

Problem (Step 14): The animals are still active.

Solution: Ensure that the agar coating made during Steps 7-9 is thin and evenly distributed. A thin and even distribution of agar is essential for proper desiccation of specimens. Work quickly during Steps 7-9 to ensure proper distribution, and discard lids that are not optimal.

Problem (Step 14): The animals are dried but do not have a tun-like appearance.

Solution: Check the relative humidity of the chamber and ensure it is $>90 \%$.

\section{DISCUSSION}

Many species of tardigrades can survive severe water loss. The rate at which different species of tardigrades can desiccate and survive varies (Wright 1989). H. exemplaris is able to survive desiccation after an initial period of slow drying (Wright 1989; Kondo et al. 2015; Boothby et al. 2017), as described in this protocol. This protocol will likely work for other species as well. The need for initially slow desiccation in many species is likely linked to their need to up-regulate production of molecules that will serve to protect them from the harmful effects of drying (Kondo et al. 2015; Boothby et al. 2017).

\section{ACKNOWLEDGMENTS}

T.C.B. is supported by the Simons Foundation in conjunction with the Life Sciences Research Foundation and by NASA grant NNX15AB44G.

\section{REFERENCES}

Boothby TC, Tapia H, Brozena AH, Piszkiewicz S, Smith AE, Giovannini I, Rebecchi L, Pielak GJ, Koshland D, Goldstein B. 2017. Tardigrades use intrinsically disordered proteins to survive desiccation. Mol Cell 65: 975-984.

Kondo K, Kubo T, Kunieda T. 2015. Suggested involvement of PP1/PP2A activity and de novo gene expression in anhydrobiotic survival in a tardigrade, Hypsibius dujardini, by chemical genetic approach. PLoS One 10: e0144803.

McNuff R. 2018. Laboratory culture of Hypsibius exemplaris. Cold Spring Harb Protoc doi:10.1101/pdb.prot102319.

Wright JC. 1989. Desiccation tolerance and water-retentive mechanisms in tardigrades. J Exp Biol 142: 267-292. 


\section{Desiccation of Hypsibius exemplaris}

Thomas C. Boothby

Cold Spring Harb Protoc; doi: 10.1101/pdb.prot102327

\begin{tabular}{rc}
$\begin{array}{r}\text { Email Alerting } \\
\text { Service }\end{array}$ & Receive free email alerts when new articles cite this article - click here. \\
\hline $\begin{array}{r}\text { Subject } \\
\text { Categories }\end{array}$ & $\begin{array}{c}\text { Browse articles on similar topics from Cold Spring Harbor Protocols. } \\
\text { Emerging Model Organisms (321 articles) } \\
\text { Laboratory Organisms, general (923 articles) }\end{array}$ \\
\hline
\end{tabular}

